\title{
Association of oral glucose tolerance test and pregnancy and fetal outcome
}

\section{Veena K. R. Bhagavan, Seemitha Shetty*, Aadhishree Rao}

Department of Obstetrics and Gynecology, A. J. Institute of Medical Sciences and Research Centre, Mangalore, Karnataka, India

Received: 20 September 2020

Accepted: 05 October 2020

*Correspondence:

Dr. Seemitha Shetty,

E-mail: seemitha90@yahoo.com

Copyright: (c) the author(s), publisher and licensee Medip Academy. This is an open-access article distributed under the terms of the Creative Commons Attribution Non-Commercial License, which permits unrestricted non-commercial use, distribution, and reproduction in any medium, provided the original work is properly cited.

\section{ABSTRACT}

Background: Gestational diabetes mellitus (GDM) affects 2-25\% of pregnancies depending on population characteristics and criteria used. It is associated with an increased risk of fetal malformation and perinatal mortality. The aim of the study was to know the prevalence of GDM, the risk factors associated with women with GDM and the feto-maternal outcome.

Methods: A prospective study conducted among 200 antenatal women attending Obstetrics and Gynaecology (OBG) Outpatient Department in A. J. Institute of Medical Sciences and Research Center from March 2019 to August 2019. GDM was diagnosed with 2-hour $75 \mathrm{gm}$ oral glucose tolerance test according to diabetes in pregnancy study group of India (DIPSI) criteria. Basic demographic details and maternal and fetal outcomes were analysed.

Results: The prevalence of GDM was high (24.5\%) compared to other studies. Normoglycemia was achieved with diet alone in $71.5 \%$, diet and metformin in $16.3 \%$ and $12.2 \%$ with insulin. Risk factors included higher body mass index (BMI) and history of GDM. Emergency caesarean rate was higher among GDM women $(\mathrm{p}<0.05)$. Fetal complications and neonatal intensive care unit (NICU) admissions were also higher in this group $(\mathrm{p}<0.001$ and $\mathrm{p}<0.05)$.

Conclusions: The higher prevalence shows the importance of early detection and timely intervention for pregnancy complicated with GDM. Due to this high-risk pregnancy, there's increased incidence of maternal and fetal outcomes which can be reduced with glycaemic control and adequate fetal surveillance.

Keywords: Gestational diabetes mellitus, Prevalence, Feto-maternal outcome, Oral glucose tolerance test, Glycaemic control

\section{INTRODUCTION}

Gestational diabetes mellitus (GDM), defined as diabetes detected at any time in pregnancy excluding overt diabetes, affects $2-25 \%$ of pregnancies depending on population characteristics and criteria used. ${ }^{1,2}$ Incidence of GDM is increasing due to lack of exercise and changing dietary habits. The disturbed carbohydrate metabolism creates maternal complications like abortions, pregnancy induced hypertension (PIH), polyhydramnios, preterm labour, fetal growth restriction (FGR) recurrent urinary infections (UTI) increased incidence of operative delivery and maternal morbidity. ${ }^{3,4}$ Pregnancies affected by GDM that are not adequately managed are consequently at risk of adverse neonatal outcomes, both immediately - shoulder dystocia, birth trauma, including birth hypoxic injuries, and neonatal hypoglycaemia and in the longer term metabolic disregulation in later childhood. ${ }^{5}$ So, it is important rule out GDM in all pregnancies. If selective screening of high-risk group alone is done, many cases may be missed.

Hence, this study is aimed to find the prevalence of GDM in a tertiary care hospital, to determine the oral glucose 
tolerance test (OGTT) value, and association of GDM and outcome of the glycaemic control with maternal and perinatal outcome.

\section{METHODS}

The study was conducted in A. J. Institute of Medical Sciences and Research Center, Mangalore. It was a prospective study conducted between March 2019 and August 2019. It included 200 antenatal women attending the Obstetrics and Gynaecology (OBG) outpatient department (OPD) during this time. After obtaining the approval of the Institutional Ethics Committee, patients were taken to be part of the study based on the inclusion and exclusion criteria.

\section{Inclusion criteria}

Singleton pregnancy, age $>18$ and <35 years, cephalic presentation were included.

\section{Exclusion criteria}

Overt diabetes, abnormal presentation, medical disorders such as hypertension and hypothyroidism, multiple pregnancies were excluded.

\section{Method of study}

All pregnant women attending the OPD at any period of their pregnancy were counselled and informed consent were taken. The principle of "universal screening" was adopted and the pregnant women underwent blood glucose test on the first prenatal visit, irrespective of the risk factors. The "Diabetes in pregnancy study group of India (DIPSI)" method was adopted. The DIPSI method is a onestep procedure: to take $75 \mathrm{gm}$ glucose dissolved in $250 \mathrm{ml}$ of water. Venous plasma glucose was estimated after 2 hours of glucose ingestion. A 2-hour plasma glucose with a cut off of $\geq 140 \mathrm{mg} / \mathrm{dl}$ was taken as diagnostic of GDM. Patients with abnormal OGTT value were investigated further for their fasting blood sugar (FBS) and post prandial blood sugar (PPBS) levels. If FBS and PPBS were normal, the patient was labelled as GDM on diet. In addition to the above, basic demographic details, patient characteristics, co-morbidities, maternal complications during pregnancy were noted.

The fetal well-being was assessed throughout pregnancy through various methods such as maternal weight gain, serial ultrasound scans, non-stress test (NST), and daily foetal movement count chart (DFMC). Doppler ultrasound was done only in selected cases. Earlier admission was done if there is any maternal or fetal compromise. Uncomplicated cases were allowed to go into spontaneous labour or wait till date. Termination was done early only in poorly controlled GDM and at times of fetal distress.

The mode of delivery, indications of caesarean and postpartum complications were noted along with neonatal outcomes such as macrosomia, hypoglycaemia, respiratory distress syndrome, seizures, anomaly, stillbirth, and intrauterine device (IUD).

\section{Statistical analysis}

Statistical analysis was performed using the chi-square test and Fisher's exact test. $\mathrm{P}$ values $<0.05$ were regarded as statistically significant.

\section{RESULTS}

Out of the 200 participants included in this study, 49 (24.5\%) were found to have 2-hour OGTT more than 140 $\mathrm{mg} / \mathrm{dl}$ and were termed GDM according to DIPSI criteria. $34 \%$ of the participants belonged to the age group 26-30 years. A total of 97 women were primigravida, while 103 women were multigravida. Majority of the women $(55.5 \%)$ had normal pre-pregnancy BMI and only $6 \%$ had history of GDM in previous pregnancy (Table 1).

Table 1: Baseline characteristics $(n=200)$.

\begin{tabular}{|c|c|c|}
\hline Characteristics & Number & $\begin{array}{l}\text { Percentage } \\
(\%)\end{array}$ \\
\hline \multicolumn{3}{|l|}{ Age in years } \\
\hline$<20$ & 1 & 0.5 \\
\hline $21-25$ & 58 & 29 \\
\hline $26-30$ & 68 & 34 \\
\hline $31-35$ & 64 & 32 \\
\hline$>36$ & 9 & 4.5 \\
\hline \multicolumn{3}{|l|}{ Parity } \\
\hline 1 & 97 & 48.5 \\
\hline 2 & 80 & 40 \\
\hline$>3$ & 23 & 11.5 \\
\hline \multicolumn{3}{|c|}{ Pre-pregnancy BMI $\left(\mathrm{kg} / \mathrm{mm}^{2}\right)$} \\
\hline Underweight $(<18.5)$ & 28 & 14 \\
\hline Normal (18.5-22.9) & 111 & 55.5 \\
\hline Overweight (23-24.9) & 55 & 27.5 \\
\hline Obese $(>25)$ & 6 & 3 \\
\hline \multicolumn{3}{|c|}{ Family history of diabetes mellitus } \\
\hline Yes & 28 & 14 \\
\hline No & 172 & 86 \\
\hline \multicolumn{3}{|c|}{ History of GDM in previous pregnancy } \\
\hline Yes & 12 & 6 \\
\hline No & 188 & 94 \\
\hline \multicolumn{3}{|c|}{ Gestational age at delivery (weeks) } \\
\hline$<34$ & 4 & 2 \\
\hline $35-36$ & 13 & 6.5 \\
\hline $37-38$ & 111 & 55.5 \\
\hline$>39$ & 72 & 36 \\
\hline
\end{tabular}

Normoglycemia was achieved with diet alone in 35 $(71.5 \%)$, diet plus metformin in $8(16.3 \%)$, and diet plus insulin in $6(12.2 \%)$ (Table 2). For the 49 patients with GDM, FBS and PPBS were done, and $61.2 \%$ were found to have higher FBS (>95 mg/dl) and only $53 \%$ had higher PPBS (>120 mg/dl). 
Table 2: Distribution of GDM and glycaemic control.

\begin{tabular}{|lll|}
\hline Distribution & Number & $\begin{array}{l}\text { Percentage } \\
(\%)\end{array}$ \\
\hline Development of GDM & & \\
\hline Yes & 49 & 24.5 \\
\hline No & 151 & 75.5 \\
\hline On treatment & & \\
\hline On diet & 35 & 71.5 \\
\hline On metformin & 8 & 16.3 \\
\hline On insulin & 6 & 12.2 \\
\hline Fasting blood sugar & & \\
\hline$<95$ & 19 & 38.8 \\
\hline $96-119$ & 20 & 40.8 \\
\hline$\geq 120$ & 10 & 20.4 \\
\hline Postprandial blood sugar & & \\
\hline$<120$ & 23 & 46.9 \\
\hline $121-159$ & 19 & 38.8 \\
\hline $160-199$ & 5 & 10.2 \\
\hline$\geq 120$ & 2 & 4.1 \\
\hline
\end{tabular}

Table 3: Distribution according to delivery and birth weight.

\begin{tabular}{|lll|}
\hline Distribution & Number & $\begin{array}{l}\text { Percentage } \\
(\%)\end{array}$ \\
\hline Mode of delivery & & \\
\hline Normal vaginal & 94 & 47 \\
\hline Induced & 22 & 11 \\
\hline Elective LSCS & 40 & 20 \\
\hline Emergency LSCS & 44 & 22 \\
\hline Indication for LSCS & & \\
\hline PROM & 11 & 13.1 \\
\hline $\begin{array}{l}\text { Cephalo-pelvic } \\
\text { disproportion }\end{array}$ & 8 & 9.5 \\
\hline Deep transverse arrest & 3 & 3.6 \\
\hline Failed induction & 2 & 2.4 \\
\hline Fetal distress & 15 & 17.8 \\
\hline Maternal request & 4 & 4.8 \\
\hline Previous LSCS & 29 & 34.5 \\
\hline Non-progression of labour & 12 & 14.3 \\
\hline Birth weight (kg) & & \\
\hline$\leq 2.4$ & 30 & 15 \\
\hline $2.5-2.9$ & 67 & 33.5 \\
\hline $3-3.9$ & 100 & 50 \\
\hline$\geq 4$ & 3 & 1.5 \\
\hline
\end{tabular}

No maternal complications were found in $24.5 \%$ of cases. Common obstetrical complications seen in this study were polyhydraminos in 8 cases, UTI in 10, premature rupture of membranes (PROM) in 15, IUD in 1, macrosomia in 1 and IUGR in 2 (Table 4). Regarding duration of pregnancy, 17 women delivered preterm and 183 delivered at term. No patients delivered past 40 weeks. Termination of pregnancy was either spontaneous, as in $47 \%$ of women, or terminated based on hospital protocols either by induction $(11 \%)$, or caesarean section $(44 \%)$. Patients who underwent emergency lower segment caesarean section (LSCS) due to either maternal or fetal indications as mentioned in Table 3. $50 \%$ of the babies were weighing between 3 and $3.9 \mathrm{~kg}$ at birth. Three mothers delivered a baby of birth weight $\geq 4 \mathrm{~kg}$ by elective LSCS, and one among them belonged the GDM group. Concerning perinatal outcome in patients with GDM, 32.2\% of the neonates had no complications. Most common complication was tachypnoea seen in $24.5 \%$ of babies, followed by respiratory distress syndrome (20\%), and jaundice $(14.2 \%)$. One of the babies had cardiac anomaly (ASD) and no neonatal deaths were noted in our study (Table 4).

Table 4: Distribution according to maternal and fetal complications.

\begin{tabular}{|lll|}
\hline Distribution & $\begin{array}{l}\text { Number } \\
(49)\end{array}$ & $\begin{array}{l}\text { Percentage } \\
(\%)\end{array}$ \\
\hline $\begin{array}{l}\text { Maternal } \\
\text { complications }\end{array}$ & \\
\hline None & 12 & 24.5 \\
\hline Polyhydramnios & 8 & 16.3 \\
\hline UTI & 10 & 20 \\
\hline PROM & 15 & 30.1 \\
\hline IUD & 1 & 2.5 \\
\hline Macrosomia & 1 & 2.5 \\
\hline IUGR & 2 & 4.1 \\
\hline Fetal complications & & \\
\hline None & 16 & 32.2 \\
\hline Fetal anomaly & 1 & 2.5 \\
\hline Hypoglycemia & 2 & 4.1 \\
\hline $\begin{array}{l}\text { Respiratory distress } \\
\text { syndrome }\end{array}$ & 10 & 20 \\
\hline Tachypnoea & 12 & 24.5 \\
\hline Neonatal death & 0 & 0 \\
\hline Large for gestational age & 1 & 2.5 \\
\hline Jaundice & 7 & 14.2 \\
\hline
\end{tabular}

Table 5: Comparison of GDM with risk factors and feto-maternal complications.

\begin{tabular}{|llll|}
\hline $\begin{array}{l}\text { Risk } \\
\text { factors/complica- } \\
\text { tions }\end{array}$ & $\begin{array}{l}\text { Patients } \\
\text { with GDM } \\
(49)\end{array}$ & $\begin{array}{l}\text { Percen } \\
\text {-tage } \\
(\%)\end{array}$ & $\begin{array}{l}\text { P } \\
\text { value }\end{array}$ \\
\hline $\begin{array}{l}\text { Higher BMI } \\
\text { (overweight and } \\
\text { obese) }\end{array}$ & 24 & 49 & $<0.01$ \\
\hline $\begin{array}{l}\text { Family history of } \\
\text { DM }\end{array}$ & 9 & 18.4 & $>0.05$ \\
\hline $\begin{array}{l}\text { History of GDM in } \\
\text { previous } \\
\text { pregnancy }\end{array}$ & 8 & 16.3 & $<0.01$ \\
\hline Emergency LSCS & 20 & 41 & $<0.05$ \\
\hline Birth weight $>$ 4 kg & 1 & 2 & $>0.05$ \\
\hline $\begin{array}{l}\text { Fetal } \\
\text { complications }\end{array}$ & 33 & 67.3 & $<0.001$ \\
\hline NICU admissions & 17 & 34.7 & $<0.05$ \\
\hline
\end{tabular}


When comparing the risk factors among the study group, those who were overweight and obese $(p<0.01)$, and who had history of GDM in previous pregnancy $(\mathrm{p}<0.01)$ had higher chances of developing GDM in the present pregnancy. Family history of diabetes mellitus had no association with GDM in this pregnancy ( $p>0.05)$. Women with abnormal OGTT had higher chances of undergoing emergency LSCS $(p<0.05)$, fetal complications $(p<0.001)$ and need for NICU admissions $(\mathrm{p}<0.05)$ than the ones with normal OGTT. Since only one woman out of 49 delivered a baby of birth weight $>4 \mathrm{~kg}$, we did not find any significant $(p>0.05)$ relation between abnormal OGTT levels and birth weight of the baby (Table 5).

\section{DISCUSSION}

GDM constitutes a metabolically distinct entity with clearly defined associated perinatal and maternal morbidities and hence need timely diagnosis and management. In this study, we performed a universal screening method with 2-hour oral glucose tolerance test with $75 \mathrm{gm}$ of glucose for detecting GDM.

The main aim of the study was to know the prevalence of GDM in women attending our tertiary care hospital, association of one abnormal OGTT value and development of GDM, and maternal and perinatal outcomes in these patients.

A $24.5 \%$ incidence of gestational diabetes was found in our study, which was higher than that of other studies and global incidence. ${ }^{6}$ Risk factors such as previous GDM and BMI $>23 \mathrm{~kg} / \mathrm{m}^{2}$ are recommended to receive early screening before 24 weeks according to guidelines followed in Australia. ${ }^{7}$ Early screening helped in detection of GDM in early stage of pregnancy and earlier opportunity for achieving normoglycemia, minimizing the adverse outcomes. The patients attending our OPD were screened for GDM, irrespective of the high-risk factors. Our study found significant correlation among overweight and obese patients and development of GDM. Kim et al concluded that GDM prevalence rates increase by BMI category, $2.3 \%$ in overweight, $4.8 \%$ in obese and $11.5 \%$ in extremely obese women. ${ }^{8}$ Patients with history of GDM in previous pregnancy is the other important predictor of adverse outcome in present pregnancy, which was similarly seen in various other studies. However, family history of diabetes mellitus showed did not show any adverse outcome in this present study, though a metaanalysis comparing these two factors revealed a positive correlation. $^{9}$

Among 49 women with GDM, almost $70 \%$ of them were euglycemic through diet and lifestyle modification alone, however $16 \%$ were started on metformin and $12 \%$ on insulin. Society of maternal-fetal medicine stated that many women can achieve euglycemia with just nutritional therapy alone, but up to 30 percent will require drug therapy. ${ }^{10}$
We found that the women diagnosed with GDM underwent emergency caesarean section more than the ones without any co-morbidities. The most common indication seen in this study was fetal distress, followed by non-progression of labour. In contrast, a study conducted by Roman et al, stating their leading cause was failed induction among the pre-GDM as well as GDM group. ${ }^{11}$

A study conducted in Punjab by Alia et al analysed the feto-maternal complications among GDM and overt DM group of women, and concluded that vaginal candidiasis (43\%), preterm labour (23\%), UTI $(23 \%)$, polyhydraminos $(17 \%)$ and preterm rupture of membranes $(10 \%)$, in descending order. Similar incidence was noted in our study, with PROM in $30 \%$, UTIs in $20 \%$ followed by polyhydraminos in $16 \%$. IUGR was seen in 2 patients with GDM in our study, with similar low incidence of $7 \%$ in Punjab study. ${ }^{12}$

Shefali et al studied the effect of diabetes on pregnancy outcomes, comparing pre GDM (PGDM; 79 women) and GDM (146 women) with non-diabetic mothers. ${ }^{13}$ They observed that abortions and low birth weight $(<2500 \mathrm{gm})$ were more common in the PGDM group than the GDM group.

Macrosomia, neonatal hypoglycemia, hyperbilirubinemia, shoulder dystocia, birth trauma and stillbirth could be the neonatal complications of women with GDM. ${ }^{14,15}$ However, tachypnoea and respiratory distress syndrome were the two most common complications faced in our study. Though we experienced no neonatal deaths, one case of cardiac anomaly was noted. Garne et al reported that multiple congenital anomalies were present in $13.6 \%$ of diabetes cases and $6.1 \%$ of non-diabetes cases. ${ }^{16}$ Parimi and Nitsch demonstrated that offspring born to mothers with any form of diabetes in pregnancy had 50\% increased risk of congenital anomalies of the kidney and the urinary tract (CAKUT). ${ }^{17}$

Alia et al reported increased incidence of hypoglycemia and macrosomia in women with GDM, but our study showed only 2 neonates with hypoglycemia and only one with birth weight of $>4 \mathrm{~kg} .{ }^{12}$

Limitations of this study included, small sample size and lack of follow up of these females to see if any developed type 2 diabetes mellitus.

\section{CONCLUSION}

The prevalence of GDM was $24.5 \%$ in our study which is slightly higher than other parts of India. The occurrence of GDM is a high-risk situation, with higher incidence of maternal and fetal adverse outcomes. All pregnant women should be screened with one step 75 gm oral glucose tolerance test for early detection and to prevent adverse outcomes by intervening on time. Those with abnormal value, should undergo further testing with FBS and PPBS. As we have seen, several factors play a role as risk factors 
for development of GDM in pregnancy, including high BMI and history of GDM in previous pregnancy. Hence early detection and tackling of these factors prior conception may play a vital role. Proper glycaemic control during pregnancy through either diet alone or anti-diabetic drugs and insulin, reduces maternal and perinatal complications. Intensive sugar control, fetal surveillance, timely delivery, and intensive neonatal care play a dynamic role. Infections, polyhydraminos, and PROM were the common maternal complications. Fetal complications include tachypnoea, respiratory distress syndrome and jaundice being the most common causes. Hence, team effort by obstetricians, endocrinologists and neonatologist is required to manage GDM effectively.

\section{ACKNOWLEDGMENTS}

The authors acknowledge the support and cooperation of all the patients involved in the study.

\section{Funding: No funding sources}

Conflict of interest: None declared

Ethical approval: The study was approved by the Institutional Ethics Committee

\section{REFERENCES}

1. Buckley BS, Harreiter J, Damm P, Corcoy R, Chico A, Simmons D, et al. Gestational diabetes mellitus in Europe: prevalence, current screening practice and barriers to screening. A review. Diabetes Med. 2012;29:844-54.

2. Sacks DA, Hadden DR, Maresh M, Deerochanawong C, Dyer AR, Metzger BE, et al. Frequency of gestational diabetes mellitus at collaborating centers based on IADPSG consensus panel-recommended criteria: the Hyperglycemia and Adverse Pregnancy Outcome (HAPO) Study. Diabetes Care. 2012;35:526-8.

3. O'Sullivan JB, Charles D, Mahan CM, Dandrow RV. Gestational diabetes and perinatal mortality rate. Am J Obstet Gynecol. 1973;116(7):901-4.

4. Harris MI. Gestational diabetes may represent discovery of pre-existing glucose intolerance. Diabetes Care. 1988;11:402-11.

5. Mitanchez D. Foetal and neonatal complications in gestational diabetes: perinatal morbidity, congenital malformations, macrosomia, shoulder dystocia, birth injuries, neonatal complications. Diabetes Metab. 2010;36:617-27.

6. Buckley BS, Harreiter J, Damm P, Corcoy R, Chico A, Simmons D, et al. Gestational diabetes mellitus in Europe: prevalence, current screening practice and barriers to screening. A review. Diabetes Med. 2012;29:844-54.

7. Nankervis A, McIntyre H, Moses R. ADIPS consensus guidelines for the testing and diagnosis of gestational diabetes mellitus in Australia, 2014. Available at: http://www.adips.org/downloads/2014 ADIPSGDMGuidelinesV18.11.2014_000.pdf. Accessed on: 25 June 2020.

8. Kim YS, England L, Wilson GH. Percentage of Gestational Diabetes Mellitus Attributable to Overweight and Obesity. Am J Pub Health. 2010;100(6):1047-52.

9. Moosazadeh M, Asemi Z, Lankarani KB. Family history of diabetes and the risk of gestational diabetes mellitus in Iran: A systematic review and metaanalysis. Diabetes Metab Syndr. 2017;11(1):99-104.

10. Society of Maternal-Fetal Medicine (SMFM) Publications Committee. SMFM Statement: Pharmacological treatment of gestational diabetes. Am J Obstet Gynecol. 2018;218(5):B2-4.

11. Tania R. Leading Cause of Primary Cesarean Delivery in Diabetic Women Is Failed Induction. Obstet Gynecol. 2020;135(1):44-5.

12. Alia A, Ahmad R, Husain M. Feto-Maternal Complications in Gestational Diabetes and in PreExisting Diabetes Mellitus. Medical Forum. 2020;31(4):45-9.

13. Shefali AK, Kavitha M, Deepa R, Mohan V. Pregnancy outcomes in pre-gestational and gestational diabetic women in comparison to nondiabetic women-A prospective study in Asian Indian mothers (CURES-35). J Assoc Physicians India. 2006;54:613-8.

14. Committee on Practice Bulletins-Obstetrics. Practice Bulletin No. 180: Gestational Diabetes Mellitus. Obstet Gynecol. 2017;130:17-37.

15. Fadda GM, D'Antona D, Ambrosini G, Cherchi PL, Nardelli GB, Capobianco G, Dessole S. Placental and fetal pulsatility indices in gestational diabetes mellitus. J Reprod Med. 2001;46:365-70.

16. Garne E, Loane M, Dolk H. Spectrum of congenital anomalies in pregnancies with pregestational diabetes. Birth Defects Res. Part A Clin. Mol Teratol. 2012;94:134-40.

17. Parimi M, Nitsch D. A Systematic Review and MetaAnalysis of Diabetes during Pregnancy and Congenital Genitourinary Abnormalities. Kidney Int Rep. 2020;5:678-93.

Cite this article as: Bhagavan VKR, Shetty S, Rao A. Association of oral glucose tolerance test and pregnancy and fetal outcome. Int J Reprod Contracept Obstet Gynecol 2020;9:4398-402. 